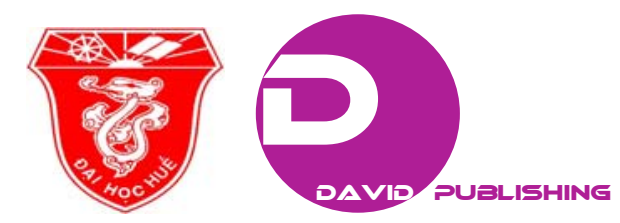

\title{
Pig Breeds (GF24) Introducing to Central Vietnam and Reproductive Performance
}

\author{
Nguyen Quang Linh and Le Duc Nhanh \\ Department of Nutritional Diseases and Systems for Livestock and Aquaculture, Center for Incubation and Technology Transfer, \\ Hue University, Hue City 47000, Vietnam
}

\begin{abstract}
The aim of this study was to characterize the reproductive performance of new pig breed introduced to Central Vietnam. The data were collected on farm by field studies with 30 individuals, during a period of one year to record and register productive and reproductive indicators. The GF24 female breeding pigs imported from US for Vietnam through GreenFeed Asia were intended for reproductive performance. Results obtained for first coming heat, first mating, first litter farrowing age, pregnancy time and dry sow were as follows: $166.2 \pm 2.94,200.44 \pm 2.14,133.79 \pm 2.29,317.75 \pm 2.19,117.31 \pm 0.31$ and $8.27 \pm 0.86$ d, respectively. The average number of piglets born alive and stillbirths per litter were $11.58 \pm 0.52$ and $0.65 \pm 0.27$, respectively; both traits were affected by the parity of the sows. The individual weight at birth of piglets was $1.38 \pm 0.12 \mathrm{~kg}$ and the number of weaned piglets was $9.58 \pm 0.53$. The feeding in the farms was characterized by using commercial feed (80\%) and agricultural remainder (20\%) as balanced feed. As a conclusion, this breed offers a potential progress in livestock for rural and industrial areas and is a contribution to the development of pig husbandry in Vietnam.
\end{abstract}

Key words: GF24 pig breed, reproductive performance, adaptation, Central Vietnam.

\section{Introduction}

Pig production systems, including backyard, free grazing, semi-intensive and intensive, are together developed in Vietnam, and the systems in the coming years will increase the number of pigs and improve productivity and meat quality by researching and putting the formula feed to new hybrid that suits the natural conditions of Vietnam. Rural and peri-urban pig farming is a form of production characterized by a low scale of activity, basically for subsistence [1]. New producers who are dedicated to this kind of industrial pig husbandry under family usually raise reproductive sows [2, 3]. The genetic quality will be improved much by exotic breeds as Pietrain, Duroc, Landrace and Yorkshire, combination breed as PIC and now introduction of GF24 for adaptability to a new environment to enable them to produce meat and reproductive performance with a minimum input.

Corresponding author: Nguyen Quang Linh, Ph.D., research fields: animal nutrition and diseases.
GF24 is a product of collaboration between two lines' harmonization of pig key PIC: 1050 line $\times 1040$ line. The 1050 line has superior characteristics of fertility with about 28 weaned/sows/year, while 1040 line is superior in weight gain and meat quality. About physical appearance, pigs GF24 have average appearance, long blow, white body, back flat, erect, small head, short muzzle, strong legs, small bones and large thigh muscles grow vertically. GF24 is a new generation line of pigs, which carries the increased appetite gene and should grow and develop very fast with low feed consumption, average gained of $1 \mathrm{~kg}$ of meat/1.1 kg bran. GF24 pigs carry the gene for increasing litter size and milk production, have a high resistant to diseases and also carry genes resistant to $E$. coli. Consistent with climate and farming conditions in Vietnam, backyard husbandry systems must be considered as a peculiar productive stratum within the context of national pig farming. They are unlikely to disappear and therefore can not be ignored, and so 
they must be studied in greater depth to know better the levels of productivity and the limitations to achieving higher rates of production. In intensive pig farms, it is common practice to routinely evaluate the system in the pursuit of greater productivity. By the way, there is a lack of information concerning levels of productivity in region and country [4]. Yet, this type of pig husbandry has many owners. Performance in a pig enterprise should be guided by specific target levels, with the aim of obtaining higher profits through an adequate business control. When pig farmer of small farm scale want to have a wide vision of the farm and regional productivity, it is essential to apply methods to illustrate this through the productive indicator analysis $[1,5,6]$. To achieve this, the producer needs a record, containing all information necessary to realize such an evaluation. Householders of pig farms in small scale generally do not have records about quantification of animal production; moreover, they rarely have access to technical support to guide them in this task. The study aimed in investigation of a new pig breed to Central Vietnam and introduction of the breed to communities to increase reproductive performance and a higher income for small scale pig farms.

\section{Materials and Methods}

\subsection{Animals and Feeding}

The observations were made from January to July 2015 , and the production data in a small industrial farm in Quang Binh imported 30 gilts of GF24 pig breed from GreenFeed Company, origin from USA, were recorded and analyzed. The type of pig prevailed in the study was the "exotic". The "improved" breeds in the farms were not included in the study. The 30 breeding stocks and gilts were allocated into five groups, each one with six gilts on eight months of age. Housing system is built in a closed model, microclimate in the barn is regulated by a system of indoor units installed in cages and fan assembly sequence at the end of the range cage to maintain proper temperatures in $22-26{ }^{\circ} \mathrm{C}$, suitable wind speeds from 1.0-1.5 m/s. Booths of sows review rectangular cage floor paved with cement plates, the floor pens have drainage systems stool, urine, toilet stalls. This system of waste resulting from the barn to the final biogas system at the waste was taken to the reservoir.

Sows are allocated into five groups, each one with six gilts, and arranged for easy coordination week care and management. Nutrients and feeding regime composed by $80 \%$ of commercial compound feed and $20 \%$ of agricultural wastes: commercial feed, $15 \%$ and 16.5\% CP, 3,100 kcal and 3,200 kcal digestible energy (DE), 5.5\% ash and 14\% moisture, and agricultural wastes as sweet potato leaves, rice bran for GF07 and GF08, respectively, are used (Table 1).

\subsection{Measurements and Methods}

The following parameters were registered: number of piglets born alive, number of stillbirths, individual and litter weight at birth and at weaning, number of weaned piglets, pre-weaning mortality, weaning age, percentage of stillborn piglets, feed conversion, and age and weight at market. The methodology used to evaluate and characterize the "runt" pigs was described by Refs. [4, 6]. The next reproductive parameters were registered as following: interval from

Table 1 Dietary composition and feeding regime.

\begin{tabular}{lccccccc}
\hline Diets & Moisture (\%) & CP (\%) & ME (kcal/kg) & CF (\%) & Ca (\%) & P (\%) & Lysine (\%) \\
\hline GF 07 & 14.0 & 15.0 & 3,100 & 10.0 & $0.9-1.5$ & $0.6-1.2$ & 0.8 \\
GF 08 & 14.0 & 16.5 & 3,200 & 6.0 & $0.9-1.5$ & $0.6-1.2$ & $0.9-1.5$ \\
\hline \multirow{2}{*}{ Feeding regime } & \multicolumn{2}{c}{ Gilt } & Pregnancy & Suckling & Dry \\
& Restricted (GF07) & Restricted (GF08) & Restricted and & ad-libitum (GF08) & Restricted (GF07) \\
\hline
\end{tabular}

CP: crude protein; ME: metabolizable energy; CF: crude fat; GF07: GreenFeed 07 line; GF08: GreenFeed 08 line. 
weaning to first service, interval from weaning to effective service, lactation period, fertility percentage, abortion percentage, productive life span, productive cycle and interval between farrowings.

The statistical analysis of the data consists of central trend measurements. An analysis of variance was performed to evaluate the effect of parity on the number of piglets born alive and dead. The model included parity and error with farms as replicates. For lactating sow, on the 23rd day the weaning is conducted, on the 20th day the caloric needs half demand amount of $3 \mathrm{~kg} / \mathrm{sow}$, and on weaned day sows not eat, but are injected able vitamins $A, D, E$ of 7 $\mathrm{mL} / \mathrm{sow}$. And sows were moved through distribution and the waiting for mating. Sows were checked and waited for insemination of sow for the coming litter. Each sow is mated two times and transferred to pregnancy crate and pens for care [1], coordinating complete of record by sow cards for herd management. After finishing coordinate, sows are kept quiet, restricted movement, kept in place coordination within 1-2 d, and then sorted sows are weekly distributed for ease of management and care. Data were processed on an Excel spreadsheet. Using some statistical parameters to characterize the degree of concentration as the mean, mean error and confidence level at $P<$ 0.05 .

\section{Results}

\subsection{Reproductive Indicators of GF24 Sows}

The results from the reproductive criteria of sows are shown in Table 2. The variables of sows GF24 and assessing fertility indicated that first mating came early but with a higher body weight $133.75 \pm 2.19 \mathrm{~kg}$ at age of $200.44 \pm 2.14 \mathrm{~d}$, and feed consumption reduced for whole periods in each cycle, thereby improving economic efficiency for farmers or investors. Age of first estrus of GF24 is $166.20 \mathrm{~d}$.

\subsection{Estrus and Insemination}

Age of first insemination of study subjects of GF24 is 200.44 d. It is lower than the set target (209 d) of the GreenFeed Company. This difference is due to the techniques applied in animal husbandry and ignores for first two estrus. The duration of standing estrus is often shorter in gilts compared to sows, but the effect of sow on estrus and ovulation timing is largely due to differences in weaning-to-estrus interval between parity groups. A sow's weaning-to-estrus interval is inversely related to the duration of estrus and onset of estrus-to-ovulation interval; sows who have short weaning-to-estrus intervals tend to have a long duration of estrus and a long onset of estrus-to-ovulation interval and vice versa.

Multiparous sows were expected to have a shorter duration of estrus and onset of estrus-to-ovulation interval. However, about the weaning-to-estrus interval, Koketsu [7] reported a shorter duration of estrus cycle for litter 1 and 2, compared to litter 3 of sows (55 h vs. 62 h; $P<0.001$ ). Table 2 also showed sows after weaning and litter one baby tended shorter duration of estrus, and had a shorter onset of estrus-to-ovulation interval than that of sows after litter four birth piglets (52.3 h vs. $54.6 \mathrm{~h}$, and $38.7 \mathrm{~h}$ vs. 42.8 h; $P<0.01$, respectively). Collectively, these data suggest that parity does have some affect on duration

Table 2 Reproductive indicators of GF24 sows $(n=30)$.

\begin{tabular}{lccc}
\hline Variables & Mean & Standard error & Probability \\
\hline First coming heat age (d) & 166.20 & 2.94 & 0.060 \\
First mating age (d) & 200.44 & 2.14 & 0.043 \\
First body weight (kg/head) & 133.79 & 2.29 & 0.047 \\
First litter age (d) & 317.75 & 2.19 & 0.044 \\
Pregnancy period (d) & 117.31 & 0.51 & 0.006 \\
Dry sow (d) & 8.27 & 0.86 & 0.010 \\
\hline
\end{tabular}


of estrus and onset of estrus-to-ovulation interval that is not related to weaning-to-estrus interval. Differences in weaning-to-estrus interval, duration of estrus and onset of estrus-to-ovulation intervals between primiparous and multifarious sows may be large enough to have important implications for the artificial insemination protocols of parity-specific herds. The volume of first insemination is also a factor affecting the productivity and quality of cubs. The study groups finding was $133.79 \mathrm{~kg} /$ head, while the GreenFeed Company's qualified set was 130-140 $\mathrm{kg} /$ head. First calving age have a close relationship with the age of first sexual activity, age of first breeding and insemination success rate for the first time. So, the first calving age is determined by age of first insemination; the insemination at early age, the breeding success rate is high, however increases duration of use sows (up to 317.75 d). The successfully mated time of weaning is an indicator affecting calving interval and reproductive performance of sows. The successful mating after weaning depends largely on the condition of stud and the body condition of sow before breeding, because too fat or too skinny will lead to slow up on pregnancy results. Time of successful insemination after weaning depends on care, sanitation and pens of sows, especially in a period of several days after birth, because it affects the recovery of the reproductive organs of sows. In addition, time of insemination after successful weaning depends on mating techniques to timely coordinate appropriate increase in pregnancy rates. To shorten the time of successful drying sows and decrease the culling rate for sows in pig farms, farmers should have concentrated the time of feeding and care after prolonged weaning sows and individuals who often get infections reproductive organs. Previous scientific results show that time after successful mating of weaning sows GF24 is $8.27 \mathrm{~d}$.

\subsection{Gestation and Farrowing}

Gestation is characteristic for the species. But besides determined by genetic factors, pregnancy is also affected by care regime. Study of pregnancy period is $117.31 \mathrm{~d}$. These results are suitable with gestation period of sow, as 110-118 d average [8, 9].

\subsection{Reproductive Performance}

To assess the fertility of sows GF24, keep track of details on the sow herself, while also monitor reproductive performance on the cubs of the study subjects. The research results are presented in Table 3. The average number of piglets born alive and stillbirths per litter were 11.58 and 0.65 , respectively. Both traits were affected by the parity of the sows. The individual weight at birth was $1.38 \mathrm{~kg}$, the number of weaned piglets was 9.58, the age and weight at marketing were $210 \mathrm{~d}$ and up to $86 \mathrm{~kg}$, respectively.

\section{Discussion}

The numbers of newborns, i.e., the total of all the offspring, include number of born alive, litter size and stillbirths. This criterion can assess whether the egg is fertilized, the technical level and stud foster care for

Table 3 Reproductive performance variables of GF24 sows $(n=30)$.

\begin{tabular}{llll}
\hline Variables & Mean & Standard errors & Probability \\
\hline Average number of piglets born alive (number) & 11.58 & 0.52 & 0.01 \\
Average number of stillbirths (number) & 0.65 & 0.27 & 0.01 \\
Weight at birth average (kg/head) & 1.38 & 0.12 & 0.00 \\
Weight at weaning average (kg/head) & 6.59 & 0.19 & 0.00 \\
Average number of weaning piglets (number) & 9.58 & 0.53 & 0.01 \\
Lactation period (d) & 23.27 & 0.36 & 0.01 \\
\hline
\end{tabular}


pregnant sows. The number of piglets born more or less depends on whether the zygote is formed and capacity of feeding pregnant sows $[1,10]$. The number of newborns/drive is the target of indirect selection to improve the number of piglets born alive per litter. In this study, the numbers of newborn are 11.58 piglets per litter. It is relatively low compared with the GreenFeed Company's standards given as 13 piglets. This difference may depend on technical conditions and ranches.

Number of piglets alive after $24 \mathrm{~h}$ is an indicator to assess the viability of the fetus, breeding capability of fetal pig and technical custody of pregnant sows of breeding farms. Research results in Table 3 shows the number of piglets alive after $24 \mathrm{~h}$ was 11.58 piglets per litter; it was lower than the company's standard of 12.45 piglets per litter and Landrace breed of 11.65 piglets per litter [11, 12] and higher than crossbred F1 (between Yorkshire and local Mong Cai breed) of 11.01 piglets per litter [5]. The number of breeding pigs selected to study was 10.24 piglets per sow, and the company's standard is 12 piglets per sow. Birth weight per litter related to the born alive and nutritional care regime affects the ability of piglet weight gain during the maternal period and post-weaning period.

Birth weight on target groups GF24 is 1.38 $\mathrm{kg} /$ piglet, and criteria of the company are 1.3-1.4 $\mathrm{kg} / \mathrm{head}$ as average weaning weight to help assess the strength of the growth of the piglets in under mother period and the maternal ability of sows. Weaning weight depends on the uniformity of the piglets at birth, survival rate, uniformity at weaning, weaning weight, number of weaned piglets per litter and technical nursing care. Weaning weight reached of $6.59 \mathrm{~kg} / \mathrm{head}$, which is still lower than other exotic breeds in Vietnam [5, 6].

The number of weaned pigs in experiments on GF24 is 9.58 piglets/litter. Number of weaned pigs is as a important indicator to assess present capabilities of the selected animal conservation. Piglets are sensitive to environmental impacts. To minimize the loss of piglets, his mother must have the appropriate technical measures, particularly preventive hygiene and stay warm for piglets. The mortality rate at birth is a lower than other breed. In addition, mortality and birth born type depend on specific regulations of each ranch. For this research, the specified volume of neonatal piglets alive after $24 \mathrm{~h}$ was selected from the householder's feedback of 0.9/piglet or more, not deformed piglets. Piglet mortality rate during follow-mother in this study was $0.65 \%$. Percentage of piglets' death during follow-mother said the number of newborn piglets alive at weaning. This indicator significantly affects economic efficiency in livestock breeding sows through the weaning amount sold $[1,8$, 10]. Percentage of piglets' death during follow-mother depends greatly on the care process of the selected piglets reared in suckling period. The piglets also depend on sows ability to care for new born piglets and the design sow crates for sow just enough to stand up and lie down so happens status sow piglets crushed the piglets to death $[9,11]$. In addition, the male piglets at this stage must be castrated after $10 \mathrm{~d}$ of age, and in the following days given creeffeed for piglets to restrict pathogens [9, 13-15]. Adjust the appropriate temperature for the sow and piglets in the demand for higher heat for piglet sow a lot [16]. When the temperature drops very low, piglet diarrhea are prone to die, and the surviving piglets were treated, but also affected very long during the growth and development of pig later. These factors affect the rate of maternal death, time to weaning (days) affects approximately suckling interval and the suckling interval must impact on two factors that shorten the weaning date and time successfully inseminated after weaning. Shortening the number of weaning days contributes to reducing the gap between the two parities, thereby increasing the parity of the sow in a year while reducing the cost of breeding and increasing economic efficiency. Weaning time for this study of GF24 is $23.27 \mathrm{~d}$. 


\section{Conclusions}

There were obvious adapted abilities of the new GF24 pig breed introduced to Central Vietnam, and reproductive performance in the local feeding combination with commercial feed under husbandry conditions in the areas were higher than native and crossbreds.

Reproductive aspects were adapted in small scale pig farms in Central Vietnam under condition of semi-intensive pig production systems. On the positive side, the use of recycled wastes is an important contribution to sustainable resource utilization, as well as being a low cost system for the producer and a higher benefit.

\section{References}

[1] Duyet, H. N., Nguyen, Q. L., Cargill, C., and Nguyen, N. P. 2010. "Effect of Using Creep Boxes for Piglets on the Reproductive Performance of Mong Cai Sows Kept in Smallholder Farms in Thuy Phuong Commune, Thua Thien Hue Province.” In Proceedings of the 14th Animal Science Congress of the Asian-Australasian Association of Animal Production Societies (AAAP), 535.

[2] Eisen, J. J., Kanis, E., and Kemp, B. 2000. "Sow Factors Affecting Voluntary Feed Intake during Lactation.” Livest. Prod. Sci. 64 (2-3): 147-65.

[3] Elbers, A. R., Vernooy, J. C., Van Den Broek, J., and Verheijden, J. H. 1996. "Risk of Recurrence of Repeat Breeding in Sows with a Repeat Breeding in the First Parity.” J. Anim. Sci. 74 (10): 2327-30.

[4] Vesseur, P. C., Kemp, B., and Den Hartog, L. A. 1994. "Factors Affecting the Weaning-to-Estrus Interval in the Sow.” J. Anim. Physiol. and Anim. Nutr. 72: 225-33.

[5] Linh, Q. N., Tu, L. C., and Koops, W. J. 1999. "The Use of Pig Large White, Mong Cai and Their Crossbreeds in Different Farming Systems in Central Vietnam.” M.Sc. thesis, Wageningen Agricultural University, The Netherlands.

[6] Linh, Q. N., Hoang, N. D., Nguyen, N. P., Cargill, C., and Trott, D. 2010. "Influence of Different Breeds, Feeding and Housing Systems on Sow Reproductive Performance in Central Vietnam.” In Proceedings of the 13th Animal Science Congress of the Asian-Australasian
Association of Animal Production Societies (AAAP), 212.

[7] Koketsu, Y. 1999. “Assessment of Sows Mating Efficacy during the Low Productive Period after Early Weaning: A Field Study.” Therio. 51 (8): 1525-32.

[8] Jindal, R., Cosgrove, J., Aherne, F. X., and Foxcroft, G. R. 1996. "Effect of Nutrition on Embryonal Mortality in Gilts: Association with Progesterone.” J. Anim. Sci. 74 (3): 620-4.

[9] Pope, W. F. 1994. "Embryonic Mortality in Swine.” In Embryonic Mortality in Domestic Species, edited by Zavy, M. T., and Geisert, R. D. Boca Raton, FL: CRC Press, 53-77.

[10] Tsuma, V. T., Einarsson, S., Madej, A., Kindahl, H., and Lundeheim, N. 1996. "Effect of Food Deprivation during Early Pregnancy on Endocrine Changes in Primiparous Sows.” Anim. Reprod. Sci. 41 (3-4): 267-78.

[11] Jindal, R., Cosgrove, J. R., and Foxcroft, G. R. 1997. "Progesterone Mediates Nutritionally Induced Effects on Embryonic Survival in Gilts.” J. Anim. Sci. 75 (4): 1063-70.

[12] Kirkwood, R. N., Baidoo, S. K., and Aherne, F. X. 1990. "The Influence of Feeding Level during Lactation and Gestation on the Endocrine Status and Reproductive Performance of Second Parity Sows.” Can. J. Anim. Sci. 70: 1119-26.

[13] Le Cozler, Y., Dagorn, J., Dourmad, J. Y., Johansen, S., and Aumaître, A. 1997. "Effect of Weaning-to-Conception Interval and Lactation Length on Subsequent Litter Size in Sows.” Livest. Prod. Sci. 51: 1-11.

[14] Tantasuparuk, W., Lundeheim, N., Dalin, A. M., Kunavongkrit, A., and Einarsson, S. 2000. "Reproductive Performance of Purebred Landrace and Yorkshire Sows in Thailand with Special Reference to Seasonal Influence and Parity Number.” Therio. 54 (3): 481-96.

[15] Tantasuparuk, W., Dalin, A. M., Lundeheim, N., Kunavongkrit, A., and Einarsson, S. 2001. "Body Weight Loss during Lactation and Its Influence on Weaning-to-Service Interval and Ovulation Rate in Landrace and Yorkshire Sows in the Tropical Environment of Thailand.” Anim. Reprod. Sci. 65 (3-4): 273-81.

[16] Koketsu, Y., and Dial, G. D. 1998. “Interactions between the Associations of Parity, Lactation Length and Weaning-to-Conception Interval with Subsequent Litter Size in Swine Herds Using Early Weaning." Prev. Vet. Med. 37: 113-20. 